Singh, V. (2019). Impact of Social Media on Social Life of Teenagers in India: A Case Study. Journal of Academic Perspective on Social Studies, (1), 13-24.

Vaka Sunumu / Case Study

Makale Geliş Tarihi: 19.02.2019

Makale Kabul Tarihi: 08.03.2019

\title{
IMPACT OF SOCIAL MEDIA ON SOCIAL LIFE OF TEENAGERS IN INDIA: A CASE STUDY
}

\begin{abstract}
Social media is playing an important role in every sphere of life now days. Computers and internet has contributed a lot in this field. Smart phones have put the entire world on a common platform. We can connect with anybody throughout the world with the help of social media. There are many social media networks to choose for the people. In this study I have selected Facebook, WhatsApp, Instagram, Twitter, YouTube and Google as the popularity of these social media networks is more among Indian youth. Other social media networks were excluded from the study. To find out the impact of media on youth we have look in to both negative and positive impacts, because everything have positive and negative aspects. The study was conducted in Shimla, the capital city of Himachal Pradesh. A sample of 200 respondents was selected having smartphone with them. The sample age group was from 15-19 years old. In this age group most of the parents allow their children to use the mobile phones. The samples were selected with the help of random-cum-purposive sampling. The study was carried out with the aim to examine the use pattern of social media by the youth of Himachal Pradesh. To conduct this study a well-structured questionnaire was developed. The collected data was analysed on percentage and average bases. The study found that there was a negative impact of social media on social life of teenagers.
\end{abstract}

Keywords: Impact, Social Media, Social Life, Youth, Himachal Pradesh, India, Use Pattern.

\section{Introduction}

Today the whole world is in the grip of information and communication technology, which has maximized the scope of exchanging the ideas with rest of the world. Modern Technology has turned the entire world into a "Global village". But it came with its negative and positive sides. Social media has reduced the entire world into a village. We can interact with the entire world with a single click. The same is applicable on the youth. Youth can exchange their ideas and information with the world and also can get the ideas and information from the world to get more opportunities of job, business, study, earning from home, etc. Social media give the opportunity to the youth to make new friends. It also helps them to maintain the old friendships.

\footnotetext{
${ }^{1}$ Guest Faculty Department of Lifelong Learning, Himachal Pradesh University, Shimla (India), 171005 e-mail ID com.vvs@gmail.com Mobile +91- 9418130058, ORCID ID: https://orcid.org/0000-0002-2265-8888
} 
Social media is also helpful for the people to trace their old departure friends. Social media is a platform where a person can express his ideas without any hesitation. With the help of social media people can work from anywhere any time. The only need to avail these facilities on social media is internet accessibility.

On the other hand it has negative aspects also. Internet is not regulated by any law. No restrictions of moral abide by. Teenagers can search anything on social media without any fear. They can search even criminal images and footages which can encourage them to attempt the criminal activities. Negative use of social media can increase the cybercrime. More use of social media can make adverse effect on their mental health and problem of addiction. It has been seen that people setting together always remain busy on their mobile phones instead of talking each other. Same is with the teenagers. They always remain busy in chatting with their online friends instead of face to face society. Teenagers are forgetting the real social world and busy in artificial world. Social medial also reduces the concentration of the people from their actual works. The study will reveal the positive and negative impact of the social media on teenagers. There are positives aspects of social media by which people can achieve a lot. But some of the negative aspects of the social media can destroy our life like mental illness and morality.

Social media has made its impact on all sections of the society. People are under the influence of internet and social media networking sites. Corporate sector is playing dominating role on all social media and making its influence on society by providing them different offers. The study is important in the manner that teenagers are under the influence of social media. They want to remain connected with the social media site more and more. The results of the study show a picture of the impact of social media on teenagers. Use of social media sites is minimum for educational purpose. Teenagers were more interested to be connected with their social media friends and society then the real society. Social activities are very important to maintain social network with the real world. But the teenagers prefer social media sites rather than to participate in social activities.

Table No. 1 Age and Sex wise Distribution of Population in India

(in 000's)

\begin{tabular}{|c|c|c|c|c|c|c|c|c|c|}
\hline \multirow{2}{*}{$\begin{array}{c}\text { Age } \\
\text { Group }\end{array}$} & \multicolumn{4}{|c|}{$\mathbf{2 0 1 1}$} & \multicolumn{3}{c|}{ 2021* $^{*}$} & \multicolumn{3}{c|}{ 2031* $^{*}$} & Persons & Males & Females & Persons & Males & Females & Persons & Males & Females \\
\hline $0-4$ & 112807 & 58632 & 54175 & 124728 & 65535 & 59193 & 120030 & 62790 & 57240 \\
\hline $5-9$ & 126928 & 66300 & 60628 & 122047 & 64265 & 57782 & 121690 & 63841 & 57849 \\
\hline $10-14$ & 132709 & 69419 & 63290 & 125583 & 66209 & 59374 & 122527 & 64417 & 58110 \\
\hline $15-19$ & 120526 & 63982 & 56544 & 126218 & 66630 & 59588 & 121225 & 63840 & 57385 \\
\hline Total & 492970 & 258333 & 234637 & 498576 & 262639 & 235937 & 485472 & 254888 & 230584 \\
\hline
\end{tabular}

Source: Office of the Registrar General, India

*Population projection by World Bank 


\section{Smartphone Users in India}

The estimated smartphone users in India were 337 million by the end of 2018. By 2022 the number of smartphone users in India would reach to 490.9 million. The growth of the smartphone users will be more than 60 percent. There were 320.57 million people accessed the internet through their mobile phones, by 2017. The projected increased in the data of internet users through mobile phone will be 462.26 million by 2021 .

\section{Review of Literature}

Badawy and Hashem (2015) conducted a study with the aim whether the use of social media has impact on academic performance of students' or not? The study concluded that there was no significant relationship between using social media and the academic performance of students'. Peter (2015) conducted a study in Lagos University to fulfil the Bachelor degree in education administration. The purpose of the study was to examine the influence of Social Media and Academic Performance of students in University of Lagos. Findings of this study show that a large number of students in University of Lagos are addicted of social media. The researcher suggested that the use of social media should also be for the purpose educational activities; researcher also suggested that Social Networking Sites should create new pages to enhance academic activities. Mensah (2016) conducted a study on the impact of social media on students' academic performance in Malaysia Tertiary Institution. The study was aimed to examining the impact of social media on academic performance. The researcher found that there was a significant impact of social media on students' academic performance in Malaysia Tertiary Institution. The researcher also concluded that time appropriateness and health addiction has a stronger significant influence on students' academic performance.

Sidiqui and Singh (2016) analysed the positive and negative aspects of Social Media. The focused areas of the study were education, business, society and youth. The findings of the study show that students can increase the quality rate of collaboration and also can increase the knowledge. Simultaneously it distracts the students. Business can be expended on social media, but there is a parallel fear of negative comments about the articles by the customer on social media. Social media can help the people to meet with each other easily. Social media can addict the people. Youngsters can stay in touch with the entire world with a click. But negative thoughts can come in their young minds and can increase the criminal activities among youngsters. Akram and Kumar (2017) studied positive and negative effect of social media on society. The focused areas of the study were health, education, business, society and youth. They researchers found that social networking has become the routine for every individual, and are dependent on technology. Networking has exposed the quality and rate of coordinated effort for students. Business persons use the social media to upgrade their business organizations. Social media has 
its own merits which influence the people positively. Yet it has demerits also which influence individuals negatively.

\section{Research Gap}

Many studies have been conducted in the field of social media. The studies have also been conducted in the areas of students. Students also belong from teenagers. But these studies have been conducted in the area of academic performance of students in different educational institutions. No study has been found related to the impact of social media on social life of teenagers. There is no study in the field of social media in Himachal Pradesh. With the help of this study the researcher will make a contribution in this field.

\section{Statement of Problem}

After the invention of internet the entire world became global platform. At present internet has become a most important source of information. People are dependent on internet for seeking the information. Different social media networking sites become the friend of an individual. It has been observed that the teenagers are more engaged in social media networking then live social activities. Smart phones and internet pack offers being provided by different telecom companies has made it easy to the teenagers to spend more time on social media networking sites. The teenagers have shifted their attention to the invisible society. No doubt social media has contributed a lot for the development of the society, but the negative aspects of the social media are matter of worry throughout the world. Therefore this problem was selected for the study.

\section{Importance of the Present Study}

The study is important, because number of social media networking sites is providing their services. Smartphone companies are launching the mobiles with new features every day. Different telecom companies are providing different offers. These offers are making the teenagers addicted of internet and social media networking. Teenage is the age where the things can easily make impact on their minds. This study will be important not only for teenagers but also for their parents. Parents can check the day to day activities of their child.

\section{Scope of the Study}

The study is mainly focused on the impact of social media on social life of teenagers. The study was conducted on the teenagers of Shimla city, a capital city of Himachal Pradesh in India. Being a capital city all the facilities like smartphones, accessibility of internet, highest learning institutions and other state offices are easily accessible in Shimla city. Technological advancement is also more in Shimla than other parts of the state. The study was restricted to six social media sites namely: Facebook, WhatsApp, YouTube, Google, Twitter and Instagram. 
These are the commonly used social media sited among teenagers. Other social media sites were excluded from the study.

\section{Sampling}

For the purpose of this research 200 samples were selected with the help of random-cumpurposive sampling. There were following conditions to select the samples:

1. Age of the sample between 15-19 years.

2. Having smartphone user.

3. Having internet pack for more than 70 days.

4. Active account on different social media sites.

By the age of 15 years parents can allow their children mobile phones. Below this age the chances of using the mobile phones are minimum. At this age teenagers remain active in their all spheres of life. That is why there was age restriction. Among the 200 samples 100 were boys and 100 were girls.

\section{Objectives of the Study}

In general the main objective of the study was to examine the impact of Social Media on the social life of teenagers in India. The other objectives were:

1. To study the use pattern of social media by the teenagers.

2. To examine the purpose of use of social media networking by the teenagers.

3. To analyse the choice of the teenagers between social media and other social activities.

\section{Hypotheses}

1. Teenagers spent more time on social media networking sites.

2. Teenagers prefer spent time with social media networking then other social activities.

\section{Data Collection}

The data was collected from primary as well as secondary resources. The primary data was collected with the help of well-structured questionnaire. Before distributing it to the sample respondents the questionnaire was distributed to five academicians having research knowledge for review and comments. After the changes suggested by the reviewers the questionnaire was finalised and a pilot survey was done on fifteen teenagers who were not part of the study. The secondary data was collected from the previous studies, internet, different libraries, etc.

\section{Limitations of the Study}

The present study is a case study of a particular city therefore the results of this study cannot be applicable on throughout the country or state. The number of samples was also small. This is mere a research paper and the time spent in this research was also not long. It is difficult to made deep generalisation within a short period of time. 


\section{Analysis of Date}

After collecting the required information with the help of questionnaire, the data was analyses. There were 100 boys and 100 girls as sample respondents. Therefore the analysis was done separately for boys and girls. The analysis was comparative between boys and girls respondents.

\section{Impact Analysis of Social Media on Teenagers}

In this section an attempt has been made to analyse the collected data by using percentage and average methods.

Table No. 2 Hours Spent on Social Media in a Day

\begin{tabular}{|c|c|c|c|c|c|}
\hline \multirow{2}{*}{ Sr. No. } & \multirow{2}{*}{ Time Spent } & \multicolumn{2}{|c|}{ Frequency } & \multicolumn{2}{c|}{ Percentage } \\
\cline { 3 - 6 } & & Boys & Girls & Boys & Girls \\
\hline 1 & $<1$ hour & 4 & 7 & 4.00 & 7.00 \\
\hline 2 & $1-3$ hours & 18 & 20 & 18.00 & 20.00 \\
\hline 3 & $4-6$ hours & 9 & 12 & 9.00 & 12.00 \\
\hline 4 & $>6$ hours & 69 & 61 & 69.00 & 61.00 \\
\hline \multicolumn{2}{|c|}{ Total } & $\mathbf{1 0 0}$ & $\mathbf{1 0 0}$ & $\mathbf{1 0 0 . 0 0}$ & $\mathbf{1 0 0 . 0 0}$ \\
\hline
\end{tabular}

Source: Field Survey

Table 2 reveals that 69 percent male teenagers and 61 percent female teenagers spend more than 6 hours on social media networking sites in a day. The above data shows that 96 percent of the male respondents and 93 percent female respondents spent more than 1 hour on social networking sites. Only 4 percent male and 7 percent female respondents spend less than 1 hour on social media networking sites.

Table No. 3 Use of Social Media Late Night

\begin{tabular}{|c|c|c|c|c|c|}
\hline \multirow{2}{*}{ Sr. No. } & \multirow{2}{*}{ Response } & \multicolumn{2}{|c|}{ Frequency } & \multicolumn{2}{c|}{ Percentage } \\
\cline { 3 - 6 } & & Boys & Girls & Boys & Girls \\
\hline 1 & Yes & 73 & 81 & 73.00 & 81.00 \\
\hline 2 & No & 27 & 19 & 27.00 & 19.00 \\
\hline \multicolumn{2}{|c|}{ Total } & $\mathbf{1 0 0}$ & $\mathbf{1 0 0}$ & $\mathbf{1 0 0 . 0 0}$ & $\mathbf{1 0 0 . 0 0}$ \\
\hline
\end{tabular}

Source: Field Survey

The data in the table 3 shows that 73 percent male and 81 percent female sample respondents opined that they use social networking sites late night. Only 27 percent male and 19 percent female respondents opined that they do not use social media networking sites late night.

Table No. 4 Purpose of Use of Social Media

\begin{tabular}{|c|c|c|c|c|c|}
\hline \multirow{2}{*}{ Sr. No. } & \multirow{2}{*}{ Purpose } & \multicolumn{2}{|c|}{ Frequency } & \multicolumn{2}{c|}{ Percentage } \\
\cline { 3 - 6 } & & Boys & Girls & Boys & Girls \\
\hline 1 & Education & 29 & 34 & 29.00 & 34.00 \\
\hline 2 & Socialization & 23 & 5 & 23.00 & 5.00 \\
\hline 3 & Chatting & 37 & 48 & 37.00 & 48.00 \\
\hline 4 & Net Surfing & 11 & 13 & 11.00 & 13.00 \\
\hline \multicolumn{2}{|c|}{ Total } & $\mathbf{1 0 0}$ & $\mathbf{1 0 0}$ & $\mathbf{1 0 0 . 0 0}$ & $\mathbf{1 0 0 . 0 0}$ \\
\hline
\end{tabular}

Source: Field Survey 
Table 4 shows that 29 percent male and 34 percent female respondents use the social media networking sites for educational purpose. 23 percent male and 5 percent female respondents use the social media networking sites for socialization. 37 percent male and 48 percent female respondents use the social media networking sites for chatting. 11 percent male and 13 percent female respondents use the social media networking sites for the purpose of net surfing.

Table No. 5 Skip/Delay Meal while using Social Media

\begin{tabular}{|c|c|c|c|c|c|}
\hline \multirow{2}{*}{ Sr. No. } & \multirow{2}{*}{ Response } & \multicolumn{2}{|c|}{ Frequency } & \multicolumn{2}{c|}{ Percentage } \\
\cline { 3 - 6 } & & Boys & Girls & Boys & Girls \\
\hline 1 & Always & 00 & 00 & 00.00 & 00.00 \\
\hline 2 & Sometimes & 81 & 92 & 81.00 & 92.00 \\
\hline 3 & Never & 19 & 8 & 19.00 & 8.00 \\
\hline \multicolumn{2}{|c|}{ Total } & $\mathbf{1 0 0}$ & $\mathbf{1 0 0}$ & $\mathbf{1 0 0 . 0 0}$ & $\mathbf{1 0 0 . 0 0}$ \\
\hline
\end{tabular}

Source: Field Survey

The data in the table 5 depicts that 81 percent male and 92 percent female respondents responded that they skip or delay their meal during use of social media network sites. Only 19 percent male and 8 percent female respondents responded that they do not skip or delay their meal while using social media network.

Table No. 6 Use of Social Media Immediate after Wake up in the Morning

\begin{tabular}{|c|c|c|c|c|c|}
\hline \multirow{2}{*}{ Sr. No. } & \multirow{2}{*}{ Response } & \multicolumn{2}{|c|}{ Frequency } & \multicolumn{2}{c|}{ Percentage } \\
\cline { 3 - 6 } & & Boys & Girls & Boys & Girls \\
\hline 1 & Always & 100 & 88 & 100.00 & 88.00 \\
\hline 2 & Sometimes & 00 & 10 & 00.00 & 10.00 \\
\hline 3 & Never & 00 & 2 & 00.00 & 2.00 \\
\hline \multicolumn{2}{|c|}{ Total } & $\mathbf{1 0 0}$ & $\mathbf{1 0 0}$ & $\mathbf{1 0 0 . 0 0}$ & $\mathbf{1 0 0 . 0 0}$ \\
\hline
\end{tabular}

Source: Field Survey

Table 6 reveals that all the male respondents always use social media networks immediate after wake up in the morning. 88 percent female respondents always use social media networks immediate after wake up in the morning. 10 percent female respondents sometimes use social media networks immediate after wake up in the morning. Only 2 percent female use social media networks immediate after wake up in the morning.

Table No. 7 Use of Social Media before Sleeping

\begin{tabular}{|c|c|c|c|c|c|}
\hline \multirow{2}{*}{ Sr. No. } & \multirow{2}{*}{ Response } & \multicolumn{2}{|c|}{ Frequency } & \multicolumn{2}{c|}{ Percentage } \\
\cline { 3 - 6 } & & Boys & Girls & Boys & Girls \\
\hline 1 & Always & 100 & 100 & 100.00 & 100.00 \\
\hline 2 & Sometimes & 00 & 00 & 00.00 & 00.00 \\
\hline 3 & Never & 00 & 00 & 00.00 & 00.00 \\
\hline \multicolumn{2}{|c|}{ Total } & $\mathbf{1 0 0}$ & $\mathbf{1 0 0}$ & $\mathbf{1 0 0 . 0 0}$ & $\mathbf{1 0 0 . 0 0}$ \\
\hline
\end{tabular}

Source: Field Survey

Table 7 reveals that all the both male and female sample respondents always use social media networking sites before sleeping in the night. 
Table No. 8 Choice between uses of Social Media Sports

\begin{tabular}{|c|c|c|c|c|c|}
\hline \multirow{2}{*}{ Sr. No. } & \multirow{2}{*}{ Choice } & \multicolumn{2}{|c|}{ Frequency } & \multicolumn{2}{c|}{ Percentage } \\
\cline { 3 - 6 } & & Boys & Girls & Boys & Girls \\
\hline 1 & Use of Social Media & 57 & 36 & 57.00 & 36.00 \\
\hline 2 & Sports & 43 & 64 & 43.00 & 64.00 \\
\hline \multicolumn{2}{|c|}{ Total } & $\mathbf{1 0 0}$ & $\mathbf{1 0 0}$ & $\mathbf{1 0 0 . 0 0}$ & $\mathbf{1 0 0 . 0 0}$ \\
\hline
\end{tabular}

Source: Field Survey

Table 8 depicts that majority (57\%) of the male respondents prefer to use social media network sites than to play sports. 36 percent female respondents prefer to use social media network sites than to play sports. 43 percent male and 64 percent female respondents prefer to play sports rather than using social media networking sites.

Table No. 9 Choice between uses of Social Media \& Talk with Family

\begin{tabular}{|c|c|c|c|c|c|}
\hline \multirow{2}{*}{ Sr. No. } & Choice & \multicolumn{2}{|c|}{ Frequency } & \multicolumn{2}{c|}{ Percentage } \\
\cline { 3 - 6 } & & Boys & Girls & Boys & Girls \\
\hline 1 & Use of Social Media & 31 & 26 & 31.00 & 26.00 \\
\hline 2 & Talk with Family & 69 & 74 & 69.00 & 74.00 \\
\hline \multicolumn{2}{|c|}{ Total } & $\mathbf{1 0 0}$ & $\mathbf{1 0 0}$ & $\mathbf{1 0 0 . 0 0}$ & $\mathbf{1 0 0 . 0 0}$ \\
\hline
\end{tabular}

Source: Field Survey

Table 9 shows that 32 percent male and 26 percent female respondents prefer to use social media network than talking with their family members, while majority of $(69 \%)$ male and $(74 \%)$ female respondents prefer to talk with their family members rather than using social media networking sites.

Table No. 10 Choice between uses of Social Media \& Social Activities

\begin{tabular}{|c|c|c|c|c|c|}
\hline \multirow[t]{2}{*}{ Sr. No. } & \multirow[t]{2}{*}{ Choice } & \multicolumn{2}{|c|}{ Frequency } & \multicolumn{2}{|c|}{ Percentage } \\
\hline & & Boys & Girls & Boys & Girls \\
\hline 1 & Use of Social Media & 56 & 63 & 56.00 & 63.00 \\
\hline 2 & Social Activities & 44 & 37 & 44.00 & 37.00 \\
\hline & Total & 100 & 100 & 100.00 & 100.00 \\
\hline
\end{tabular}

Source: Field Survey

The data in the table 10 shows that teenagers prefer to use social media networking rather than participating in social activities. Majority of (56\%) male respondents and (63\%) female respondents prefer to use social media networking rather than participating in social activities.

Table No. 11 Keep Mobile Date (Internet) on

\begin{tabular}{|c|c|c|c|c|c|}
\hline \multirow{2}{*}{ Sr. No. } & \multirow{2}{*}{ Response } & \multicolumn{2}{|c|}{ Frequency } & \multicolumn{2}{c|}{ Percentage } \\
\cline { 3 - 6 } & & Boys & Girls & Boys & Girls \\
\hline 1 & 24 Hours & 38 & 22 & 38.00 & 22.00 \\
\hline 2 & $\begin{array}{c}\text { Throughout the Day, } \\
\text { But not in the Night }\end{array}$ & 33 & 61 & 33.00 & 61.00 \\
\hline 3 & $\begin{array}{c}\text { When use Social } \\
\text { Media Networking }\end{array}$ & 29 & 17 & 29.00 & 17.00 \\
\hline & Total & $\mathbf{1 0 0}$ & $\mathbf{1 0 0}$ & $\mathbf{1 0 0 . 0 0}$ & $\mathbf{1 0 0 . 0 0}$ \\
\hline
\end{tabular}

Source: Field Survey 
Table 11 reveals that 38 percent male respondents and 22 percent female respondents keep the mobile data on 24 hours. 33 percent female respondents and 61 percent female respondents keep their mobile data on throughout the day but not in the night, while 29 percent male and 17 percent female respondents switch the mobile data on only when they use social media networking sites.

\section{Findings of the Study}

Most of the teenagers spend more time on social networking site.

$>$ Results show that the respondents use social media networks less for educational purpose.

$>$ Majority of the respondents from both the categories sometimes skip or delay their meal while using social media networking.

$>$ Almost all the respondents from both categories use social media networking site immediate after wake up in the morning and before sleeping in the night.

$>$ Majority of the male respondents prefer to use social media networking and female respondents prefer sports activities.

$>$ Respondents from both male and female categories prefer to talk with their family members rather than using social media networking sites.

$>$ Majority of the respondents from both the categories do not want to perform social activities.

$>$ Very few respondents from both the categories switch their mobile data on when they uses the social media networking sites.

\section{Discussion}

The main focus of the present study was to examine the impact of the social media on social life of teenagers. It is evident from the above analysis of the responses given by the respondents, that teenagers spent their lot of time on social networking site. More use of mobiles causes stress and mental illness among teenagers. It also creates addiction among them. Teenagers use social media networking till late night and do not sleep timely. Sleeplessness causes insomnia among the teenagers. Few teenagers use social media networks for educational purpose. There may be misuse of social media sites, if they do not use it for educational purpose. Criminal activities can be attempted by misusing the social media sites.

Teenagers even skip or delay their meal while using social media networking. Skip or delay in meal causes illness among teenagers. At this stage food and nutrients are very important for human being. Participating in sports keeps the young minds healthy, but teenagers prefer to use social media networking than participating in sports activities. During the study it was found that the teenagers prefer to talk with their family members rather than using social media networking site. This is good for both teenagers as well as their parents to understand each other. 
Teenagers prefer to use social media networking instead of performing social activities. It causes isolation of the teenagers with the real society. Teenagers most of the time keeps internet on at their mobile phones. It causes different life threatening diseases due to dangerous rays.

After the advancement of the technology the responsibilities of the parents and teachers towards teenagers have become more than earlier. It is the responsibility of the parents to check the day to say activities of their children. Parents should spent more time with their children and should talk on different issues. They should also talk about the negative and positive aspects of social media. The parents should motivate their children to abide by the positive aspects of the social media sites and also should motivate them to watch the motivational video clippings. The teachers should deliver special lectures on negative effect of social media. Teachers can organise a competition among their students to write about the effects of social media and can provide rewards to the best performers in front of all the students. Time management should also be taught to the students at school level, so that they can manage their social life, study and use of social media networking sites in balance manner. We cannot separate the teenagers from use of social media, but can motive them to go with the positive side of the social media networking sites.

The study conducted by Badawy and Hashem reveals that there was no significant relationship between using social media and the academic performance of students'. The study of the Peter depicts that a large number of students in in the study area were addicted of social media. In the present study it was also found that the teenagers were also addicted of social media. The study of Mensah shows that there was a significant impact of social media on students' academic performance in Malaysia Tertiary Institution. The study also reveals that time appropriateness and health addiction has a stronger significant influence on academic performance of students'. Sidiqui and Singh revealed in their study that students can increase the quality rate of collaboration and also can increase the knowledge. The study conducted by Akram and Kumar found that social networking has become the routine for every individual, and are dependent on technology. Networking has exposed the quality and rate of coordinated effort for students.

During the review of literature, the researcher went through the previous studies. There were many studies on the impact of social media on students' academic performance. Some of the previous studies were available on the impact of social media on society. No previous studies were found on the present issue. The results of the previous studies had also shown the negative impact of social media on students or society. The findings of the present study also show the negative impact of social media on social life of teenagers.

\section{Conclusion}

The study was conducted to analyse the impact of social media on social life of teenagers. Excess use of social media was found among. Lack of live socialization was also found. Skip or 
delay in meal also causes adverse-effect on their health may be causes malnutrition among teenagers. With the development of technology the entire world become a common market for all of us. We cannot stay away from this market. This is the era of technology and modernization. There is competition in every sphere of life. Internet is playing a vital role in our life, whether it is teenagers, young, old, male or female. Everyone is under the influence of internet networking. We can say that slowly the world is being dependent on internet. We cannot deny the contribution of internet and other social media in the development. But there are some negative aspects also. All the things are easily available online. Everybody can search the material according to his or her choice. The right to choice is good, if we choose the right things.

\section{Acknowledgement}

It gives me immense pleasure to pay my sincere gratitude to the respondents for their opinion about the research problem. I sincerely extend my deep sense of gratitude to my wife Dr. Sapna Sharma for her cooperation during this study.

\section{References}

Akram, W. and Kumar, R., (2017), A Study on Positive and Negative Effects of Social Media on Society, International Journal of Computer Science and Engineering (open access), Vol.5, Issue 10, October, 2017, ISSN (e): 2247-2693, pp. 347-354.

Bhardwaj, Akashdeep, Avasthi, Vinay and Groundar, Sam, (2017), Impact of Social Networking on Indian Youth-A Survey, International Journal of Electronics and Information Engineering, Vol. 7, No. 1, September, 2017, (DOI: 10.6636/IJEIE.201709.7(1).05), pp. 41-51.

El-Badawy, Tarek, A., and Hashem, Yasmin, (2015), The Impact of Social Media on the Academic Development of School Students, International Journal of Business Administration, Vol. 6, No. 1, November 2015, ISSN (e): 1923-4015, (p): 1923-4007, pp. 46-52.

Mensah, Sandra Okyeadie (2016), The Impact of Social Media on Students, Academic Performance-A Case of Malaysia Tertiary Institution, International Journal of Education, Learning and Training, Vol. 1, (No. 1), November, 2016, ISSN: 2289-6694, pp. 14-21.

Peter, Osharive, (2015), Social Media and Academic Performance of Students in University of Lagos, B. A. Research Project, Submitted to the Department of Education Administration, Faculty of Education, University of Lagos for the Degree in Education Administration. 
Shahjahan, A. T. M. and Chisty, Kutub Uddin, (2014), Social Media Research and its Effect on our Society, International Scholarly and Scientific Research \& Innovation, Vol. 8, No. 6, ISNI: 0000000091950263, pp. 2009-2013.

Siddiqui, Shabnoor and Singh, Tajinder, (2016), Social Media its Impact with Positive and Negative Aspects, International Journal of Computer Applications Technology and Research, Vol. 5, Issue 2, ISSN: 2319-8656, pp. 71-75. 